\title{
Prevalence of anxiety, depression and post- traumatic stress disorder among Ebola survivors in northern Sierra Leone: a cross- sectional study
}

Abdulai Jawo Bah ${ }^{1,2,3+}$, Peter Bai James ${ }^{3, *^{*}}$, Nuhu Bah ${ }^{5}$, Amara Bangali Sesay ${ }^{5}$, Stephen Sevalie ${ }^{6}$ and Joseph Sam Kanu ${ }^{7}$

\begin{abstract}
Background: There is limited data available on the long-term mental health impact of Ebola virus disease (EVD) on survivors despite the disease experience of survivors meeting the criteria of a traumatic event as defined in the Diagnostic and Statistical Manual of Mental Disorders version IV (DSM IV). This study aimed to assess the prevalence and predictive factors of anxiety, depression and posttraumatic stress disorder among EVD survivors, approximately 2 years after discharge from the Ebola treatment centre (ETC).

Methods: We conducted a cross-sectional study between May and August 2017 among 197 adults Ebola survivors in Bombali district, Northern Sierra Leone. We collected information about demographics, mental health status and possible predictive factors. The HAD scale was used to measure anxiety and depression. PTSD was measured using the PTSD-checklist (PCL). Chi-square test or Fisher exact two-tailed tests were used to test for associations and the multiple logistic regressions model to determine factors that were independently associated with the outcome variables.

Results: The mean anxiety, depression and PTSD scores were $(5.0 \pm 3.9),(7.1 \pm 3.8)$ and (39.5 \pm 6.4$)$ respectively. Based on cut-off scores, the prevalence of anxiety (HADs score $\geq 8$ ), depression (HADs score $\geq 8$ ) and PTSD (PCL $\geq 45$ ) among Ebola survivors were $(n=49,24.9 \%)$, $(n=93,47.2 \%)$ and $(n=43,21.8 \%)$ respectively. Older Ebola survivors ( $\geq 30$ years) were more likely to show symptoms of depression ( $\mathrm{AOR}=8.5,95 \% \mathrm{Cl}: 2.68-27.01, p=0.001$ ) and anxiety ( $\mathrm{AOR}=3.04 ; 95 \% \mathrm{Cl}$ : 1.2-7.7, $p=0.019)$ compared to younger ones (<30 years). In addition, Ebola survivors who experienced a decreased level of exercise post-ETC discharge were more likely to show symptoms of depression ( $\mathrm{AOR}=2.63 ; 95 \% \mathrm{Cl}: 1.25-5.54, p=0.011$ ) and anxiety (AOR $=3.60 ; 95 \% \mathrm{Cl}: 1.33-9.72, p=0.012$ ) compared to those whose exercise remained the same post-ETC discharge.

* Correspondence: jamepeb@yahoo.com

${ }^{+}$Abdulai Jawo Bah and Peter Bai James contributed equally to this work.

${ }^{3}$ Faculty of Pharmaceutical Sciences, College of Medicine and Allied Health

Sciences, University of Sierra Leone, Freetown, Sierra Leone

${ }^{4}$ Australian Research Centre in Complementary and Integrative Medicine,

School of Public Health, Faculty of Health, University of Technology Sydney,

Sydney, New South Wales, Australia

Full list of author information is available at the end of the article

C C The Author(s). 2020 Open Access This article is licensed under a Creative Commons Attribution 4.0 International License, which permits use, sharing, adaptation, distribution and reproduction in any medium or format, as long as you give appropriate credit to the original author(s) and the source, provide a link to the Creative Commons licence, and indicate if changes were made. The images or other third party material in this article are included in the article's Creative Commons licence, unless indicated otherwise in a credit line to the material. If material is not included in the article's Creative Commons licence and your intended use is not permitted by statutory regulation or exceeds the permitted use, you will need to obtain permission directly from the copyright holder. To view a copy of this licence, visit http://creativecommons.org/licenses/by/4.0/ The Creative Commons Public Domain Dedication waiver (http://creativecommons.org/publicdomain/zero/1.0/) applies to the data made available in this article, unless otherwise stated in a credit line to the data. 


\begin{abstract}
(Continued from previous page)
Conclusion: Our findings show that anxiety, depression and PTSD are common among the Ebola survivors in Bombali district, Northern Sierra Leone, and that underscores the need to diagnose and manage mental health morbidities among Ebola survivors long after their recovery from Ebola virus disease. Cognitive Behaviour Therapy (CBT) and Interpersonal Therapy (IPT) need to be explored as part of overall mental healthcare package interventions.
\end{abstract}

Keywords: Anxiety, Depression, Post-traumatic stress disorder, Ebola, Ebola survivor, Sierra Leone

\section{Background}

The West African Ebola virus disease (EVD) outbreak was the largest and worst compared to all previous outbreaks combined since it was discovered in 1976 [1]. It recorded an average case fatality rate of $51 \%$, ranging from $41 \%$ in Sierra Leone to $61 \%$ in Guinea [2]. This resulted in 28,616 cases, 11,310 deaths and over 10,000 survivors across the three worst affected countries (Sierra Leone, Liberia and Guinea) [3]. Sierra Leone recorded 8704 infected cases, 3589 deaths, including 221 health workers [4]. It is estimated that a little over 4000 survived the EVD, many of which are experiencing post-Ebola physical and mental health sequelae [5-8].

The psychosocial consequences of the 11-year civil war (1991-2002) in Sierra Leone identified the need for mental health services. It also created an increased interest in mental health among researchers, policymakers, service users and carers, religious bodies, non-governmental organisations, civil society and healthcare providers. This lead to the establishment of mental health coalition in 2011 [9] and the enactment of the Mental Health Policy in 2012, which serves as a framework for the development of mental health services [10]. Despite this progress, access to quality mental health services is still a challenge as there are health system and community barriers that limit the delivery of effective mental health service [11]. Currently, Sierra Leone has two psychiatrists, two Clinical Psychologists and 19 mental health nurses that provide service to 7 million population [12]. Although the recent Mental Health Strategic Plan 2014-2018 provides a roadmap for the development of mental health curriculum, mental health course at tertiary health training institutions are still relatively non-existence [13]. The recent Ebola epidemic and mudslide further highlighted the dire need for mental health services considering the trauma affected communities (Ebola and mudslide survivors) were exposed to during and after such a devastating health and disaster emergencies respectively [5, 14]. A study in Western Urban and Western Rural districts of Sierra Leone indicated that EVD risk behaviours were significantly associated with symptoms of depression and post-traumatic stress disorder (PTSD) in the general population [15]. A nationwide survey also found that anxiety, depression and PTSD symptoms were prevalent in the general population a year after the end of the EVD response [16]. With the care of Ebola survivors integrated within the existing free health care program for pregnant women, lactating mothers and under-five children [17], it is expected Ebola survivors will have increased access to health services including mental health. To provide better mental health services to Ebola survivors, an understanding of the mental health status and their needs is crucial in informing policy and practice, which will improve resources to address mental health service gaps in Sierra Leone.

A review of the literature suggests that several sociodemographic and lifestyle characteristics have been shown to be associated with anxiety, depression and PTSD. For example, high rates of anxiety and depression were reported among females than males [18-20]. Also, low physical activity has been reported to be associated with an increased rate of anxiety and depression [21, 22]. In addition, studies have reported an association between increased alcohol intake and the development of anxiety and depressive symptoms among the general and sub-health populations [23-25].

Despite the disease experience of EVD survivors meeting the criteria of a traumatic event as defined in the DSM IV [26], there is a paucity of data with regards the longterm mental health impact among survivors. Several studies reported varying degree of psychiatric morbidity (depression, anxiety and post-traumatic stress disorder) among survivors in Guinea [27, 28], Liberia [29] and Sierra Leone [30-32]. Most of these studies were conducted at the peak of the outbreak using brief symptom-based tools and small sample sizes. Also, the Sierra Leonean studies failed to determine the socio $=$ demographic and health-related correlates of the symptoms of anxiety, depressions and posttraumatic disorder. Thus, the aim of this study was to determine the prevalence and predictive factors of anxiety, depression and posttraumatic stress disorder among EVD survivors 2 years after discharge from an Ebola treatment centre (ETC).

\section{Method}

\section{Study design and settings}

We conducted a cross-sectional study among Ebola survivors residing in the Bombali district, Northern Sierra Leone, who visit the Bombali EVD Survivor Care Clinic. The Bombali EVD, Survivor Care Clinic, was established in October 2015 as a result of a partnership among the following institutions-Direct Relief, Medical Research Centre (MRC), and University of Makeni (UNIMAK), 
the Sierra Leone Ministry of Health and Sanitation (MoHS) and the Bombali EVD Survivor Association. The clinic provides outpatient services to survivors residing in the Bombali district and its environs. The clinic also provides referral services if needed to specialised care, at tertiary public health facilities within and outside the district. The services provided in the clinic include but are not limited to eye health, mental health awareness raising and sensitisation about Ebola survivorship.

\section{Sociodemographic characteristics and other Ebola-related variables}

The sociodemographic characteristics include age $(\leq 30$ years, $30-49$ years and $>50$ years) sex (male / female), level of education (No formal education, primary, secondary and tertiary) marital status (single, married, divorced and widowed) and monthly income (< Le500, 000, Le 500,000Le1, 000,000 and > Le1000, 000). Ebola-related variables explored include their past medical history of psychiatric illness prior to being diagnosed of Ebola (yes/no), the effect of the death of friend or relative (Not affected, slightly affected, badly affected and not applicable), number of current post-Ebola sequelae (none, 1-2 and > 2) and number of emotional support (none, 1-2 and $>2$ ), knowledge of a relative or friend who died of Ebola (yes/no), alcohol status before (yes/no) and after Ebola (yes/no) and level of exercise after Ebola (increased, decreased, remain the same, not applicable) and alcohol intake after Ebola (increased, decreased, remain the same, not applicable).

\section{Main outcomes measures}

Anxiety and depression among Ebola survivors were assessed using the Hospital Anxiety and Depression (HADS) Scale. The (HADS) Scale is a 14-item scale used to measure symptoms of anxiety and depression in the hospital, primary healthcare facility and among the general population [33]. The choice to use HADS scale was informed by the fact that it has been used to measure anxiety and depression among survivors of a similar post-infectious disease outbreak such as Severe Acute Respiratory Syndrome (SARS) [34]. The HADS scale has previously been used in Sierra Leone among ex-Ebola Treatment Centre (ETC) staff [35]. The HADS scale consists of seven items for the anxiety subscale and seven for the depression subscale. The anxiety subscale focused on symptoms of generalised anxiety disorder, and the depression subscale focused on anhedonia, which is considered the main symptom of depression [36]. Ebola survivors were asked to tick a particular response that they think is closest to how they have been feeling in the past week. Each of the 14 items was scored on a response scale with four alternatives that ranged from 0 to 3 . The total score for each participant ranges from 0 to 21 . Higher scores implied higher anxiety and depression levels. For both anxiety and depression, we used the recommended cut off score of 8 and above according to a clinically tested classification of psychiatric morbidity [33, 37, 38]. A score of $\geq 8$ indicates a possible case of anxiety and depression, [33, 37, 38]. The HADS scale presents high internal consistency; Cronbach's alpha coefficient was 0.884 ( 0.829 for anxiety and 0.840 for depression) and stability (test-retest intra-class correlation coefficient 0.944 ) with high concurrent validity [33]. Permission to use the HADS scale was obtained from GL Assessment Limited (Supplementary file 1).

The PTSD- checklist (PCL), a 17-item self-report measure of the 17 Diagnostic and Statistical Manual of Mental Disorders, Fourth Edition (DSM-IV) symptoms of PTSD was used to assess their level of PTSD among Ebola survivors. The PCL has been used to screen individuals for PTSD, diagnose PTSD, and monitor symptom change during and after treatment [39]. Intrusion, avoidance, and hyperarousal were considered as the primary domains of measurement with a higher internal consistency coefficient (Cronbach's alpha of 0.939). Respondents indicate how much they have been bothered by a symptom over the past month using a 5-point (1-5) Likert scale. Responses ranged from 1 (Not at All) to 5 (extremely). We calculated the total symptom severity score (range $=17-85$ ) for each participant [40]. A total score (45-85) was considered as a possible case of PTSD. A higher cut-off point score was used to identify definite cases and to minimise false positives [40]. The index trauma for PTSD in our study was the time of EVD diagnosis, and the time since the index trauma occurred to the time of data collection between 18 and 36 months. The PCL has been used in Sierra Leone among ex-Ebola Treatment Centre (ETC) staff [35] and other West African populations [41]. We did not obtain permission to use this tool given that this tool is available freely online and not copyrighted [42].

\section{Patient population and sampling method}

A convenience sampling method was employed to recruit Ebola survivors into our study. An Ebola survivor was defined in our study as an adult (18 years and older) with a confirmed positive result on RT-PCR testing for Ebola virus on any body fluid who was treated successfully and discharged and with an EVD discharge certificate [43]. Ebola survivors attending the clinic during the period of data collection were recruited into the study. EVD survivor status was confirmed by comparing the clinic's register with the Sierra Leone Association of Ebola Survivors registry of patients residing in the Bombali District and its environs, regardless of where they were originally treated. We excluded survivors who had severe physical or mental sequelae such as earing problems that limit their participation in the study. 


\section{Data collection procedure}

The data collection period was between May and August 2017, and it was done either by face-to-face interview in Krio (widely spoken language in Sierra Leone) for those who were illiterate or through self-administration of the anxiety, depression and PTSD instruments (for those who were literate). We initially piloted anxiety, depression and PTSD instruments among 10 EVD survivors whose data were excluded in the final data analysis. We explored the possibility of using self-administered and intervieweradministered formats of data collection during the piloting of the study instruments. No significant difference was observed between the two data collection procedures based on the feedback we received. To ensure that we collect accurate information using both data collection formats, the self-administered format was only allowed for survivors with tertiary education who indicated their willingness to answer the questions on their own.

We also sent the study instruments to public health, infectious disease and mental health experts for review. This was followed by group discussions among researchers, linguistic expert and data collectors to reach a consensus in a bid to minimise error during the data collection process. We trained two pharmacy professionals, a community health officer and a nurse from the Bombali District Health Management Team (DHMT) as data collectors on the overall research protocol, informed consent, confidentiality, data collection techniques and quality assurance. We held a stakeholder meeting with the management of the clinic and the DHMT, where we explained the full protocol of the research. The clinic coordinator approached adults Ebola survivors attending the clinic during the period of data collection. EVD survivors were invited to take part in the study after explaining to them about the research. EVD survivors were taken through the participant information sheet, the informed consent form and those that consented and signed or thumb-printed the informed consent form were interviewed. Participants were informed of their right to opt-out of the study at any point if they wish to discontinue without any explanation, and that they would not receive direct benefit from participating, other than the psychosocial support they will receive for those that score above the threshold.

\section{Ethical clearance}

The Sierra Leone Ethics and Scientific Review Committee, Ministry of Health and Sanitation gave ethical approval before the start of the study. Written informed consent was obtained from participant either by signing or thumb printing (illiterate participants) the consent form.

\section{Data analysis}

Data analysis was done using SPSS Package version 24 (SPSS, Inc.; Chicago). Descriptive statistics such as means and standard deviation as well as frequency and percentages were used to report continuous and categorical variables respectively. Chi-square or Fisher exact was used to test for associations between the independent variables (age, sex, marital status, number of emotional supports etc) and outcome variables (anxiety, depression and post-traumatic stress disorder). In the univariate, bivariate and multivariate analysis, anxiety, depression and PTSD scores were converted into binary variable based on their respective cut-off scores. A score of $<8$ was considered as no possible case of anxiety and depression. A score $\geq 8$ was considered as a possible case of anxiety and depression. With regards to PTSD, a score $<45$ was considered as no possible case of PTSD. A score $\geq 45$ was considered as a possible case of PTSD. Independent variables, i.e. demographic and health-related variables with $p$-value $\leq 0.25$ in the bivariate analysis, i.e. Chi-square or Fisher exact test, were entered into the univariate model in order to determine the odd crude ratio. Independent variables with $p \leq 0.05$ were then entered into the multivariable logistic regression model to determine factors that were independently associated with outcome variables (anxiety, depression and PTSD). Statistical significance was defined as a two-tailed, $p$-value less than 0.05 for all inferential analysis.

\section{Results}

\section{Sociodemographic characteristics of Ebola survivors}

Of 245 Ebola survivors approached, 197 agreed to participate in the study giving a response rate of $80.4 \%$. Table 1 summarises the sociodemographic characteristics of Ebola survivors. Majority ( $n=167,84.8 \%$ ) were below the age of 50 years, and half $(n=99,50.3 \%)$ of them were females. Close to half $(n=84,42.6 \%)$ were single. More than twothird ( $n=140,71.1 \%)$ were badly affected as a result of the death of a friend or a relative due to Ebola, whereas the exercise level among more than half $(n=110,55.8 \%)$ of survivors decreased after recovery. Our study adheres to the STROBE guidelines for cross-sectional studies. Please see supplementary file 2 for details.

\section{Prevalence of anxiety, depression and PTSD}

Table 2 presents the summary statistics of the anxiety, depression and PTSD. The mean anxiety, depression and PTSD scores were $(5.0 \pm 3.9),(7.1 \pm 3.8)$ and $(39.5 \pm$ 6.4) respectively. Table 2 also indicates that close to a quarter $(n=49,24.9 \%)$, close to half $(n=93,47.2 \%)$ and close to a quarter $(n=43,21.8 \%)$ of survivors interviewed showed a possible case of anxiety, depression and PTSD respectively.

\section{Association between anxiety, depression, PTSD and demographic variables}

Table 3 highlights the association between anxiety, depression, PTSD and the demographic variables. Age, death of friend or relative, alcohol intake before Ebola, 
Table 1 demographics of Ebola survivors $(n=197)$

\begin{tabular}{|c|c|c|}
\hline Characteristics & Variables & $\mathrm{N}(\%)$ \\
\hline \multirow[t]{3}{*}{ Age Group } & $<30$ years & $87(44.2)$ \\
\hline & $30-49$ years & $80(40.6)$ \\
\hline & $\geq 50$ years & $30(15.2)$ \\
\hline \multirow[t]{2}{*}{ Sex } & Male & $98(49.7)$ \\
\hline & Female & $99(50.3)$ \\
\hline \multirow[t]{4}{*}{ Marital status } & Single & $84(42.6)$ \\
\hline & Married & $59(29.9)$ \\
\hline & Divorced & $13(6.6)$ \\
\hline & Widow/widower & $41(20.8)$ \\
\hline \multirow[t]{3}{*}{ Monthly income level } & $<$ Le500, 000 & $141(71.6)$ \\
\hline & $\begin{array}{l}\text { Le } 500,000-\text { Le1, } \\
000,000\end{array}$ & $52(26.4)$ \\
\hline & >Le1000, 000 & $4(2.0)$ \\
\hline \multirow[t]{4}{*}{ Educational status } & $\begin{array}{l}\text { Non-formal } \\
\text { education }\end{array}$ & $73(37.1)$ \\
\hline & Primary education & $32(16.2)$ \\
\hline & $\begin{array}{l}\text { Secondary } \\
\text { education }\end{array}$ & $68(34.5)$ \\
\hline & Tertiary education & $24(12.2)$ \\
\hline \multirow[t]{3}{*}{ Number of emotional support } & None & $7(3.6)$ \\
\hline & $1-2$ & $70(35.5)$ \\
\hline & $>2$ & $120(60.9)$ \\
\hline \multirow[t]{4}{*}{ Effect of death of friend or relative } & Not affected & $9(4.6)$ \\
\hline & Slightly affected & 29(14.7) \\
\hline & Badly affected & $140(71.1)$ \\
\hline & Not applicable & 19(9.6) \\
\hline \multirow{3}{*}{$\begin{array}{l}\text { Number of current post-Ebola } \\
\text { sequelae }\end{array}$} & None & $22(11.2)$ \\
\hline & $1-2$ & $45(22.8)$ \\
\hline & $>2$ & $130(66.0)$ \\
\hline \multirow{2}{*}{$\begin{array}{l}\text { Past psychiatric history prior to } \\
\text { being diagnosed with Ebola }\end{array}$} & Yes & $8(4.1)$ \\
\hline & No & 189(95.9) \\
\hline \multirow[t]{2}{*}{ Alcohol intake before Ebola } & Yes & $60(30.5)$ \\
\hline & No & $137(69.5)$ \\
\hline \multirow[t]{4}{*}{ Alcohol intake after Ebola } & Increased & $12(6.1)$ \\
\hline & Decreased & $31(15.7)$ \\
\hline & Remain the same & 23(11.7) \\
\hline & Not applicable & $131(66.5)$ \\
\hline \multirow[t]{4}{*}{ Level of exercise after Ebola } & Increased & $33(16.8)$ \\
\hline & Decreased & $110(55.8)$ \\
\hline & Remain the same & $50(25.4)$ \\
\hline & Not applicable & $4(2.0)$ \\
\hline \multirow{2}{*}{$\begin{array}{l}\text { Knowledge of relative or friend death } \\
\text { due to Ebola }\end{array}$} & Yes & 179(90.9) \\
\hline & No & $18(9.1)$ \\
\hline
\end{tabular}

level of exercise after Ebola and knowing a relative or a friend that died due to Ebola was associated with the symptoms of anxiety among survivors. Number of emotional supports received age, the number of post-Ebola symptoms experienced, alcohol intake before and after Ebola and level of exercise after Ebola were associated with symptoms of depression among survivors. However, no sociodemographic and health-related characteristics were associated with symptoms of PTSD among survivors.

Predictors of anxiety, depression and PTSD among Ebola survivors

Tables 4 and 5 indicate that older Ebola survivors $(\geq 30$ years) were more likely to show symptoms of depression $(\mathrm{AOR}=8.5,95 \% \mathrm{CI}: 2.68-27.01, p=0.001)$ and anxiety $(\mathrm{AOR}=3.04 ; 95 \% \mathrm{CI}: 1.2-7.7, p=0.019)$ compared to younger ones ( $<30$ years). In addition, Ebola survivors who experience a decreased level of exercise post-ETC discharge were more likely to show symptoms of depression $(\mathrm{AOR}=2.63 ; 95 \% \mathrm{CI}: 1.25-5.54, p=0.011)$ and anxiety $(\mathrm{AOR}=3.60 ; 95 \% \mathrm{CI}: 1.33-9.72, p=0.012)$ compared to those whose exercise remained the same post-ETC discharge. On the other hand, Table 6 shows that none of the sociodemographic variables considered in our study was a predictor of PTSD among survivors.

\section{Discussion}

Several studies have reported the prevalence of symptoms of psychological distress among Ebola survivors immediately after being infected or shortly after discharge from the Ebola treatment centre $[5,6]$. However, there is paucity of data on the long-term mental health effects among those who survived Ebola virus disease. This is the first ever-quantitative study that assessed the long-term prevalence and predictors of the symptoms of anxiety, depression and post-traumatic stress disorder among Ebola survivors in Sierra Leone. Our study is aimed to provide an insight into the long-term psychological morbidity and its possible risk factors among Ebola survivors in Sierra Leone in order to inform ongoing policy and practice related to providing care to Ebola survivors.

Our study indicates that close to a quarter $(24.9 \%)$ of survivors exhibited a possible case of anxiety which is slightly higher than those reported by Nanyonga et al. [31] and Mohamed et al. [44] in Kenema, Eastern Sierra Leone. Although studies from East Africa [45-47] and in Guinea [28], Nigeria [48] Liberia [49] and within Sierra Leone [30, 50-52] using quantitative and qualitative research designs have reported that psychological harm is common among Ebola survivors, it has failed to assess anxiety among Ebola survivors specifically, and this makes comparison among studies to be difficult. For instance, a study by Ji et al. in Sierra Leone, anxiety was part of positive symptom distress index (PSDI) that was used to evaluate psychological 
Table 2 Prevalence of anxiety, depression and PTSD

\begin{tabular}{lll}
\hline Anxiety scale & Mean (SD) & $5.0(3.9)$ \\
Depression scale & Possible case of anxiety (HADS cut-off score $\geq 8) n(\%)$ & $49(24.9)$ \\
& Mean (SD) & $7.1(3.8)$ \\
PTSD scale & Possible case of depression (HADs cut-off score $\geq 8) n(\%)$ & 93(47.2) \\
& Mean (SD) & 39.5(6.4) \\
\hline
\end{tabular}

distress among Ebola survivors, medical personnel and logistics workers [51]. In reporting, only the PSDI score was reported, and it was higher among Ebola survivors compared to non-survivors [51].

With regards to depression, our study indicates that close to half (47.2\%) of Ebola survivors interviewed show possible case of depression. Our result is slightly above a similar study conducted in Liberia among 82 survivors, 6 months following their discharge from ETC [53] It is also higher than the prevalence reported among survivors in eastern Sierra Leone (35\%) that were assessed 4 months post-ETC discharge [31].. In addition, a cohort study in Guinea among survivors most of which were assessed 8 months post-ETC discharge, reported a lower prevalence of depressive symptoms (15\%) although three, thirteen and eleven of the 33 survivors who were assessed by a psychiatrist show mild, moderate and severe depression respectively [54]. Self-perceived depression was reported in $1 \%$ of survivors in another Guinean study [27]. The variation observed between our finding with that of other findings from other studies may be due to differences in the post ETC discharge time when Ebola survivors were assessed. It may also be due to the use of different evaluation tools to assess depression as well as the varied sociocultural dynamics and coping mechanisms employed by survivors in each of the study areas.

Post-traumatic stress disorder is a mental disorder that is common among individuals that have experienced severe trauma such a war, sexual violence or deadly infectious disease outbreak such as EVD. Our study reports that close to a quarter (21\%) of EVD survivors interviewed, showed a possible case of PTSD. A similar prevalence of post-traumatic stress reactions three-four weeks post-ETC discharge which is predictive of PTSD was reported in a study by Hugo and colleagues in Kailahun-Eastern Sierra Leone [30]. The reason for such similarity in our findings may be due to coincidence. Future nationwide studies should explore whether our findings hold true in other parts of Sierra Leone and other Ebola-affected countries. Compared to other infectious disease outbreaks, in our study, our PTSD prevalence is slightly lower than that reported on SARS survivors in Hong Kong [34]..

Our study revealed that symptoms of anxiety and depression were more common among survivors above the age of 30 years and whose rate of exercise has decreased after surviving Ebola. Low physical activity was found to be associated with anxiety and depression among chronic disease patients in Myanmar and Vietnam [22]. Physical activity should be part of mental health promotion interventions given that increase physical activity and low sedentary behaviour are known to improve depressive $[21,55]$ and anxiety [56] symptoms in survivors of other chronic disease conditions. In addition to physical exercise, evidence-based mental health interventions such as Behavioural Activation (BA) need to be explored as part of mental health care interventions given that BA- as part of the Youth Readiness Intervention (YRI) - has been proven to be effective in the treatment of symptoms of common mental disorders such as depression among war-affected youths in Sierra Leone. Although further research into our reported associations is needed, our findings suggest that being old and decreased physical activity, which might be due to the widely reported musculoskeletal complications among EVD survivors [7] may be specific risk factors for anxiety and depression among Ebola survivors and may warrant early and focused support services. Even though studies have reported a positive correlation between increased alcohol intake and high rates of anxiety and depression [23-25], results from our regression analyses did not find alcohol intake as a statistically significant predictor of anxiety, depression and PTSD among Ebola survivors. Differences in sample population, socio-economic and cultural context as well as in the use of study instruments may help explain why there were no significant associations between alcohol intake and anxiety, depression as well as PTSD. Further large-scale studies are required to ascertain whether a positive association between alcohol intake and anxiety, depression as well as PTSD.

We observed in our study that none of the sociodemographic variables considered is a possible predictor of symptoms of post-traumatic stress disorder experienced by survivors although a study among Severe Acute Respiratory Syndrome (SARS) survivors reported that being female and the presence of chronic health condition diagnosed before being infected with SARS were predictors of PTSD among SARS survivors in Hong Kong [57]. It is worthy to note that even though the general literature suggests that the rates of depression and anxiety can be higher among females than males [18-20,58,59], analysis of our 


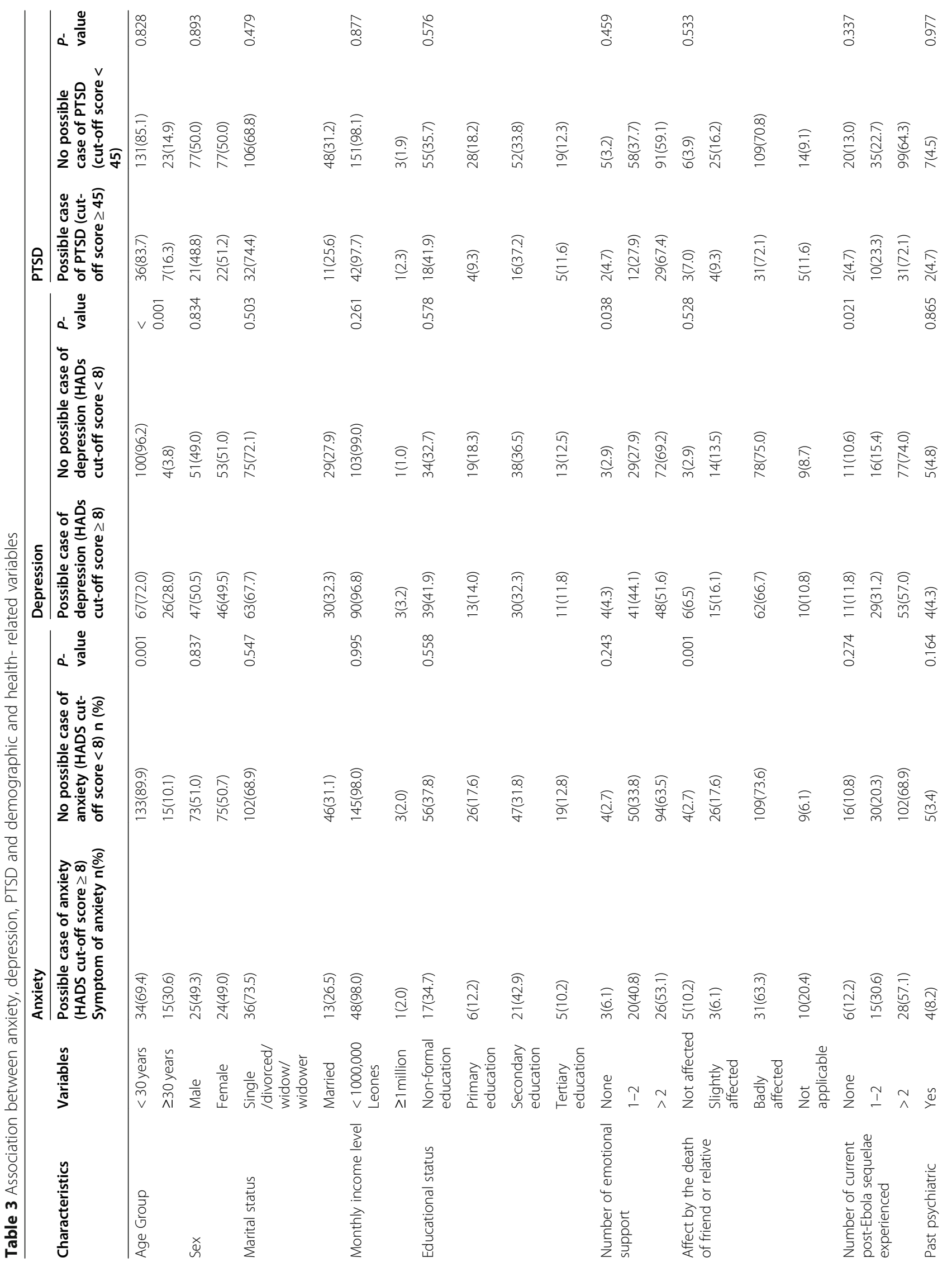




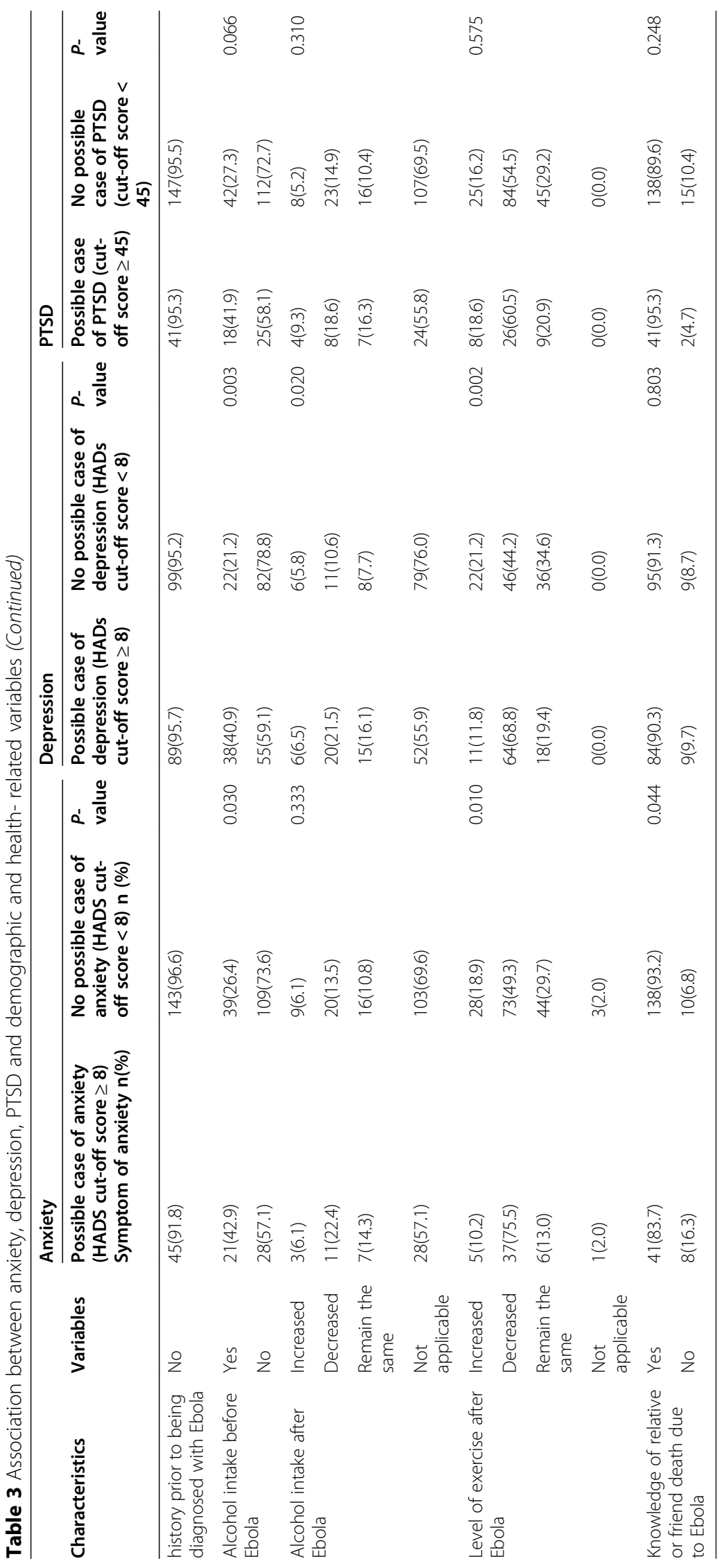


Table 4 Predictors of anxiety among Ebola survivors

\begin{tabular}{|c|c|c|c|c|c|}
\hline Characteristics & Variables & OR $(95 \% \mathrm{Cl})$ & $P$-value & Adjusted OR $(95 \% \mathrm{Cl})$ & $P$-value \\
\hline \multirow[t]{2}{*}{ Age Group } & $<30$ years & 1 & 0.001 & 1 & 0.019 \\
\hline & $\geq 30$ years & $3.91(1.74-8.78)$ & & 3.04(1.20-7.70) & \\
\hline \multirow[t]{3}{*}{ Number of emotional support } & None & 1 & & - & \\
\hline & $1-2$ & $0.53(0.11-2.60)$ & 0.437 & - & \\
\hline & $>2$ & $0.37(0.08-1.75)$ & 0.210 & - & \\
\hline \multirow[t]{4}{*}{ Effect of death of friend or relative } & Not affected & 1 & & 1 & \\
\hline & Slightly affected & $0.09(0.02-0.55)$ & 0.009 & $0.04(0.01-0.32)$ & 0.002 \\
\hline & Badly affected & $0.23(0.06-0.90)$ & 0.035 & $\mathbf{0 . 1 2}(0.03-0.58)$ & 0.008 \\
\hline & Not applicable & $0.89(0.18-4.38)$ & 0.885 & $\mathbf{0 . 5 1}(0.09-3.03)$ & 0.462 \\
\hline \multirow[t]{2}{*}{ Past psychiatric history } & No & 1 & 0.178 & - & \\
\hline & Yes & $2.54(0.66-9.87$ & & - & \\
\hline \multirow[t]{2}{*}{ Alcohol intake before Ebola } & No & 1 & 0.031 & 1 & \\
\hline & Yes & $2.10(1.07-4.11)$ & & $1.93(0.85-4.35)$ & 0.115 \\
\hline \multirow[t]{3}{*}{ Level of exercise after Ebola } & Remains the same & 1 & & 1 & \\
\hline & Increased & $1.20(0.35-4.14)$ & 0.774 & $1.30(0.34-4.50)$ & 0.700 \\
\hline & Decreased & $3.40(1.40-8.26)$ & 0.007 & $\mathbf{3 . 6 0}(1.33-9.72)$ & 0.012 \\
\hline \multirow[t]{2}{*}{ Knowledge of relative or friend death due to Ebola } & No & 1 & 0.051 & - & - \\
\hline & Yes & $0.37(0.14-1.00)$ & & - & - \\
\hline
\end{tabular}

data suggest that there is no statistically significant association between the rates of depression and anxiety and gender in our study (see Table 3). Reasons for this may be due to differences in the traumatic event that triggered their psychological distress, in this case, being infected with the Ebola virus. It may also be due to differences in resilience/ coping mechanism developed in responding to the traumatic event. Another reason maybe linked to the sample size used and the fact that a non-probability sampling method was used in our study.

Policy and clinical implications and future direction In light of the relatively high prevalence of symptoms of anxiety, depression and PTSD, the care for Ebola

Table 5 Predictors of depression among Ebola survivors

\begin{tabular}{|c|c|c|c|c|c|}
\hline Characteristics & Variables & OR $(95 \% \mathrm{Cl})$ & $P$-value & Adjusted OR(95\%Cl) & P-value \\
\hline \multirow[t]{2}{*}{ Age Group } & $<30$ years & 1 & $<0.001$ & 1 & 0.001 \\
\hline & $\geq 30$ years & $9.70(3.24-29.06)$ & & $8.51(2.68-27.01)$ & \\
\hline \multirow[t]{3}{*}{ Number of emotional support } & None & 1 & & - & \\
\hline & $1-2$ & $1.06(0.22-5.10)$ & 0.942 & - & \\
\hline & $>2$ & $0.50(0.11-2.33$ & 0.378 & - & \\
\hline \multirow[t]{3}{*}{ Number of sequelae experienced } & None & 1 & & - & \\
\hline & $1-2$ & $1.81(0.64-5.10)$ & 0.260 & - & \\
\hline & $>2$ & $0.69(0.28-1.70)$ & 0.419 & - & \\
\hline \multirow[t]{2}{*}{ Alcohol intake before Ebola } & No & 1 & 0.003 & 1 & \\
\hline & Yes & $2.58(1.38-4.82)$ & & $0.10(0.24-4.21)$ & 0.998 \\
\hline \multirow[t]{4}{*}{ Alcohol intake after Ebola } & Increased & $1.52(0.47-4.97)$ & 0.489 & 2.68(0.47-15.18) & 0.265 \\
\hline & Decreased & $2.76(1.22-2.64)$ & 0.015 & $1.63(0.36-7.43)$ & 0.531 \\
\hline & same & $2.85(1.13-7.20)$ & 0.027 & $1.67(0.32-8.83)$ & 0.546 \\
\hline & Not drinking & 1 & & 1 & 1 \\
\hline \multirow[t]{3}{*}{ Level of exercise after Ebola } & Remains the same & 1 & & 1 & \\
\hline & Increased & $1.00(0.40-2.51)$ & 1.00 & $0.84(0.29-2.43)$ & 0.747 \\
\hline & Decreased & $2.78(1.41-5.50)$ & 0.003 & $2.63(1.25-5.54)$ & 0.011 \\
\hline
\end{tabular}


Table 6 Predictors of Post-traumatic stress disorder (PTSD) among Ebola survivors

\begin{tabular}{|c|c|c|c|c|c|}
\hline Characteristics & Variables & $\begin{array}{l}\text { OR } \\
(95 \% \mathrm{Cl})\end{array}$ & $\begin{array}{l}P- \\
\text { value }\end{array}$ & $\begin{array}{l}\text { Adjusted } \\
\text { OR }\end{array}$ & $\begin{array}{l}P \text { - } \\
\text { value }\end{array}$ \\
\hline \multirow{2}{*}{$\begin{array}{l}\text { Alcohol intake before } \\
\text { Ebola }\end{array}$} & No & 1 & & & \\
\hline & Yes & $\begin{array}{l}1.92(0.95- \\
3.87)\end{array}$ & 0.069 & - & \\
\hline \multirow{2}{*}{$\begin{array}{l}\text { Knowledge of relative } \\
\text { or friend death due } \\
\text { to Ebola }\end{array}$} & No & 1 & & & \\
\hline & Yes & $\begin{array}{l}2.38(0.53- \\
10.77)\end{array}$ & 0.261 & - & \\
\hline
\end{tabular}

survivors should not only focus on the treatment of physical conditions. Healthcare workers providing care to survivors should be aware of the possible long-term psychological complications, especially symptoms of anxiety, depression and PTSD. As it has been reported in previous studies among the general population in Sierra Leone $[15,16]$, our study further highlights the significance of detecting and managing psychiatric morbidity among survivors following a devastating and traumatic event or an infectious disease outbreak such as Ebola.

For future outbreaks or other traumatic events, the design and execution of response during and after the outbreak should factor in the high possibility of the increasing incidence of mental health morbidities as it has been observed in other infectious disease outbreaks [60]. The training of mental health staff and the integration of mental health into the existing primary healthcare system will contribute to improving access to psychosocial care in a country where access to mental health care is limited. Psychosocial support with self-copying strategies is needed to enhance survivors' resilience in dealing with anxiety, depression and PTSD. The application of disaster response management knowledge and skills can be useful while awaiting further research evidence on the effectiveness of psychosocial interventions given the fact that Ebola shares a similar clinical pattern of psychiatric morbidity with other disasters. The Cognitive-behavioural therapy (CBT) is a mental health intervention that can be used to manage psychiatric morbidity among survivors in Sierra Leone given that previous Sierra Leonean studies have reported the effectiveness of CBT in improving the mental health, social behaviour, and school functioning among waraffected youth [61] and ex-Ebola Treatment Centre staff [35]. Also, the use of group interpersonal therapy (IPT) needs to be explored as it was effective in treating depressive symptoms in Uganda [62] and South Africa [63].

Future longitudinal cohort studies are required to understand the trajectory of mental health morbidities among Ebola survivors. Multicentre or cross-country studies are needed to unearth any cultural differences that may exist and come up with findings that are applicable to a wider population. The psychological impact of Ebola on at risk populations such as pregnant women, children, immediate relatives of Ebola survivors and survivors of recent natural disaster in Sierra Leone is an area worth exploring.

\section{Strengths and limitations}

To the best of our knowledge, this is the first study that has explored the long-term psychological complications among Ebola survivors in Sierra Leone. However, the interpretation of our findings should be done with caution, considering the following limitations. Our findings are only representative of Bombali district and not the whole of Sierra Leone. Although we used widely used prevalidated instruments to measure anxiety, depression and PTSD, none of them was validated in Sierra Leone before the conduct of our study. As such, we were unable to validate the clinical cut-off point for anxiety, depression and PTSD among the Ebola survivors that participated in our study. Instead, we used clinical cutoff points based on the available literature [33, 36, 37, 40]. In addition, comparison of our findings with others was difficult since, to the best of our knowledge, these studies used different tools to measure symptoms of anxiety, depression and PTSD among the Ebola survivors. Our study was conducted without a control group, and that makes interpretation of our findings is little bit challenging. In our study, we rely on self-report to measure anxiety, depression and PTSD as well as retrospective reporting of some of the sociodemographic and lifestyle characteristics. As such, we cannot totally rule out the possibility of recall bias. We excluded Ebola survivors with hearing impairment, which may limit their ability to provide information accurately. Although the demographic characteristics of Ebola survivors excluded are similar to those included in our study, it is possible that those excluded may have provided different responses to questions asked in our study. The index trauma for PTSD in our study was the time of EVD diagnosis. However, we were unable to report the time since the index trauma occurred to the time of data collection for each Ebola survivors.

Owing to the cross-sectional design, the present study only described anxiety, depression and PTSD symptoms of Ebola survivors 2 years after the end of the Ebola outbreak in Sierra Leone. Longitudinal studies are required in order to monitor changes over time.

\section{Conclusion}

Our study suggests that anxiety, depression and PTSD are common among Ebola survivors in Bombali district, Northern Sierra Leone. Also, our findings suggest that being above the age of 30 years and decreased rate of exercise after surviving Ebola are likely predictors of anxiety and depression but PTSD among Ebola survivors. Our study further underscores the importance of detecting and 
managing mental health morbidities among survivors after exposure to an infectious disease outbreak such as Ebola. Cognitive Behaviour Therapy (CBT) and Interpersonal Therapy (IPT) need to be explored as part of overall mental healthcare package interventions.

\section{Supplementary information}

Supplementary information accompanies this paper at https://doi.org/10. 1186/s12889-020-09507-6.

Additional file 1: Supplementary file 1. Countersigned User Agreement for the use of HADS. Countersigned user agreement for the use of HADS in this study between GL Assessment Limited and the Corresponding Author.

Additional file 2: Supplementary file 2. STROBE checklist for crosssectional studies. Adherence to STROBE guidelines for cross-sectional studies.

\section{Abbreviations}

AOR: Adjusted odd ratio; CBT: Cognitive-behavioural therapy; DHMT: District Health Management Team; DSM-IV: Manual of mental disorders, fourth edition; EVD: Ebola virus disease; ETC: Ebola treatment centre; HADS: Hospital Anxiety and Depression Scale; IPT: Interpersonal therapy; MoHS: Ministry of Health and Sanitation; PTSD: Post-traumatic stress disorder; SARS: Severe acute respiratory syndrome; WHO: World Health Organisation

\section{Acknowledgements}

We extend our sincere thanks and appreciation to Ebola survivors who took part in the study. We also extend our gratitude the staff of the Ebola survivor clinic, Bombali DHMT, Ebola survivor Association Bombali district and data collectors for their assistance.

\section{Authors' contributions}

AJB conceived of the study and contributed to the study design and the writing of the first draft of the manuscript and revising the subsequent manuscript drafts. PBJ contributed in the study design, analysed the data, interpreted the results and contributed in writing the first draft of the manuscript as well as revising the subsequent manuscript drafts. NB and ABS contributed to study design, supervised data collection and revised the subsequent manuscript draft. SS and JSK contributed to study design and contributed intellectual content of the manuscript. All authors read and approved the final version of the manuscript.

\section{Funding}

The study was self-funded by the authors.

\section{Availability of data and materials}

The datasets used for the current study are available from the corresponding author on reasonable request (abdulaijawobah@yahoo.com and jamepeb@yahoo.com).

\section{Ethics approval and consent to participate}

The Sierra Leone Ethics and Scientific Review Committee, Ministry of Health and Sanitation gave ethical approval before the start of the study. Written informed consent was obtained from participant either by signing or thump printing (illiterate participants) the consent form.

\section{Consent for publication}

Not applicable.

\section{Competing interests}

The authors declare that they have no competing interests.

\section{Author details}

${ }^{1}$ Faculty of Basic Medical Sciences College of Medicine and Allied Health Sciences University of Sierra Leone, Freetown, Sierra Leone. ${ }^{2}$ Institute for Global Health and Development, Queen Margaret University Edinburg, Musselburgh, Scotland, UK. ${ }^{3}$ Faculty of Pharmaceutical Sciences, College of
Medicine and Allied Health Sciences, University of Sierra Leone, Freetown, Sierra Leone. ${ }^{4}$ Australian Research Centre in Complementary and Integrative Medicine, School of Public Health, Faculty of Health, University of Technology Sydney, Sydney, New South Wales, Australia. ${ }^{5}$ Directorate of Drugs and Medical Supplies Ministry of Health and Sanitation, Freetown, Sierra Leone. ${ }^{6} 34$ Military Hospital Wilberforce, Freetown, Sierra Leone. ${ }^{7}$ Directorate of Disease Prevention and Control, Ministry of Health and Sanitation, Freetown, Sierra Leone.

Received: 23 May 2019 Accepted: 6 September 2020

Published online: 11 September 2020

\section{References}

1. Dixon MG, Schafer IJ, Centers for Disease C, Prevention. Ebola viral disease outbreak--West Africa, 2014. MMWR Morb Mortal Wkly Rep. 2014:63(25):548-51.

2. WHO. WHO: Ebola response roadmap situation report 1. In: WHO: Ebola response roadmap situation report. Geneva: SWl; 2014

3. Ebola Situation Report - 30 March 2016. Available from http://apps.who.int/ ebola/current-situation/ebola-situation-report-30-march-2016. Accessed 17 Mar 2019.

4. WHO-Sierra Leone: Statement on the end of the Ebola outbreak in Sierra Leone. 2017 https://www.afro.who.int/news/statement-end-ebola-outbreaksierra-leone. Accessed 17 Feb 2019

5. James PB, Wardle J, Steel A, Adams J. Post-Ebola psychosocial experiences and coping mechanisms among Ebola survivors: a systematic review. Tropical Med Int Health. 2019:24(6):671-91.

6. Lotsch F, Schnyder J, Goorhuis A, Grobusch MP. Neuropsychological longterm sequelae of Ebola virus disease survivors - a systematic review. Trave Med Infect Dis. 2017;18:18-23.

7. Vetter P, Kaiser L, Schibler M, Ciglenecki I, Bausch DG. Sequelae of Ebola virus disease: the emergency within the emergency. Lancet Infect Dis. 2016; 16(6):e82-91.

8. James PB, Wardle J, Steel A, Adams J. An assessment of Ebola-related stigma and its association with informal healthcare utilisation among Ebola survivors in Sierra Leone: a cross-sectional study. BMC Public Health. 2020; 20(1):182.

9. Shackman J, Price BK. Mental health capacity building in northern Sierra Leone: lessons learned and issues raised. Intervention. 2013;11(3):261-75.

10. Minstry of Health and Sanitation GOSL. Mental Health Policy. Government of Sierra Leone. Ministry of Health and Sanitation. In: Freetown Ministry of Health and Sanitation; 2012.

11. Bah AJ, Idriss A, Wurie $H$, Bertone M, Elimian $K$, Horn R, Samai M: A Scoping Study on Mental Health and Psychosocial Support (MHPSS) in Sierra Leone. 2018 https://www.qmu.ac.uk/media/5362/mhpss-scoping-review-14092018. pdf Accessed 23 Mar 2019

12. WHO Sierra Leone Annual Report: A Year in Focus 2017. https://www.afro who.int/sites/default/files/2018-03/World\%20Health\%200rganization\%2 OSierra\%20Leone\%20Annual\%20Report\%202017.pdf. Accessed 2 Apr 2019.

13. Alemu W, Funk M, Gakurah T, Bash-Taqi D, Bruni A, Sinclair J, Kobie A, Muana A, Samai M, Eaton J. WHO profile on mental health in development (WHO proMIND): Sierra Leone. Geneva: WHO; 2012

14. UNDAC: Sierra Leone: Landslide and Floods Situation Update \#8-31 August 2017. 2017 https://reliefweb.int/sites/reliefweb.int/files/resources/Sierra\%2 OLeone\%20Sit\%20Update\%20no\%208.pdf Accessed 12 Apr 2019.

15. Betancourt TS, Brennan RT, Vinck P, VanderWeele TJ, Spencer-Walters D, Jeong J, Akinsulure-Smith AM, Pham P. Associations between mental health and Ebola-related health behaviors: a regionally representative crosssectional survey in post-conflict Sierra Leone. PLoS Med. 2016;13(8): e1002073.

16. Jalloh MF, Li W, Bunnell RE, Ethier KA, O'Leary A, Hageman KM, Sengeh P, Jalloh MB, Morgan O, Hersey $\mathrm{S}$, et al. Impact of Ebola experiences and risk perceptions on mental health in Sierra Leone, July 2015. BMJ Glob Health. 2018;3(2):e000471.

17. Sierra Leone Government directs that all health facilities should provide free health care for Ebola survivors. https://cocorioko.net/sierra-leonegovernment-directs-that-all-health-facilities-should-provide-free-health-carefor-ebola-survivors/. Accessed 21 Feb 2019.

18. Baxter AJ, Scott KM, Ferrari AJ, Norman RE, Vos T, Whiteford HA. Challenging the myth of an "epidemic" of common mental disorders: trends in the global prevalence of anxiety and depression between 1990 and 2010. Depress Anxiety. 2014;31(6):506-16. 
19. Bekker MHJ, van Mens-Verhulst J. Anxiety disorders: sex differences in prevalence, degree, and background, but gender-neutral treatment. Gender Med. 2007:4:S178-93.

20. Bener A, Ghuloum S, Abou-Saleh MT. Prevalence, symptom patterns and comorbidity of anxiety and depressive disorders in primary care in Qatar. Soc Psychiatry Psychiatr Epidemiol. 2012;47(3):439-46.

21. Patsou ED, Alexias GD, Anagnostopoulos FG, Karamouzis MV. Effects of physical activity on depressive symptoms during breast cancer survivorship: a meta-analysis of randomised control trials. ESMO Open. 2017;2(5):e000271

22. Pengpid S, Peltzer K. High sedentary behaviour and low physical activity are associated with anxiety and depression in Myanmar and Vietnam. Int J Environ Res Public Health. 2019;16(7):1251.

23. Kuria MW, Ndetei DM, Obot IS, Khasakhala LI, Bagaka BM, Mbugua MN, Kamau J. The association between alcohol dependence and depression before and after treatment for alcohol dependence. ISRN Psychiatry. 2012; 2012:482802.

24. Martinez P, Neupane SP, Perlestenbakken B, Toutoungi C, Bramness JG. The association between alcohol use and depressive symptoms across socioeconomic status among 40- and 45-year-old Norwegian adults. BMC Public Health. 2015;15(1):1146.

25. Coulson CE, Williams LJ, Berk M, Lubman DI, Quirk SE, Pasco JA. Association between alcohol consumption and self-reported depression among elderly Australian men. Geriatr Ment Health Care. 2014;2(1):3-8.

26. American Psychiatric Association: Diagnostic and statistical manual of mental disorders (DSM-5 $\left.{ }^{\oplus}\right)$ Fifth Edition. Washington, D.C: American PsychiatricAssociation; 2013.

27. Qureshi Al, Chughtai M, TO L, Kolie JP, Camara HFS, Ishfaq MF, N'Dour CT, Beavogui K. Study of Ebola virus disease survivors in Guinea. Clin Infect Dis. 2015:61(7):1035-42.

28. Etard JF, Sow MS, Leroy S, Toure A, Taverne B, Keita AK, Msellati P, Magassouba N, Baize S, Raoul H, et al. Multidisciplinary assessment of postEbola sequelae in Guinea (Postebogui): an observational cohort study. Lancet Infect Dis. 2017;17(5):545-52

29. Wilson HW, Amo-Addae M, Kenu E, Ilesanmi OS, Ameme DK, Sackey SO. Post-Ebola syndrome among Ebola virus disease survivors in Montserrado County, Liberia 2016. Biomed Res Int. 2018. article number 1909410. https:// doi.org/10.1155/2018/1909410.

30. Hugo M, Declerck H, Fitzpatrick G, Severy N, Gbabai O, Decroo T. Posttraumatic stress reactions in Ebola virus disease survivors in Sierra Leone. Emerg Med (Los Angel). 2015;5(6):1-4.

31. Nanyonga M, Saidu J, Ramsay A, Shindo N, Bausch DG. Sequelae of Ebola Virus Disease, Kenema District, Sierra Leone. Clin Infect Dis. 2016;62(1):125.

32. Howlett P, Walder A, Lisk D, N'jai A, Lado M, Brown C, Sevalie S, Sesay F, Semple M, Scott J. Neurological and psychiatric manifestations of post Ebola syndrome in Sierra Leone. Lancet. 2017;389:S48.

33. Zigmond AS, Snaith RP. The hospital anxiety and depression scale. Acta Psychiatr Scand. 1983;67(6):361-70.

34. Mak IWC, Chu CM, Pan PC, Yiu MGC, Chan VL. Long-term psychiatric morbidities among SARS survivors. Gen Hosp Psychiatry. 2009;31(4): 318-26.

35. Waterman S, Hunter ECM, Cole CL, Evans LJ, Greenberg N, Rubin GJ, Beck A. Training peers to treat Ebola Centre workers with anxiety and depression in Sierra Leone. Int J Soc Psychiatry. 2018;64(2):156-65.

36. Snaith RP. The hospital anxiety and depression scale. Health Qual Life Outcomes. 2003;1:29.

37. Bjelland I, Dahl AA, Haug TT, Neckelmann D. The validity of the hospital anxiety and depression scale: an updated literature review. J Psychosom Res. 2002;52(2):69-77.

38. Olssøn I, Mykletun A, Dahl AA. The hospital anxiety and depression rating scale: a cross-sectional study of psychometrics and case finding abilities in general practice. BMC Psychiatry. 2005;5(1):46.

39. Blanchard EB, Jones-Alexander J, Buckley TC, Forneris CA. Psychometric properties of the PTSD checklist (PCL). Behav Res Ther. 1996;34(8):669-73.

40. Weathers FW, Litz BT, Keane TM, Palmieri PA, Marx BP, Schnurr PP: The ptsd checklist for dsm-5 (pcl-5). Scale available from the National Center for PTSD at www ptsd va gov 2013, 10.

41. Okulate GT, Jones OB. Post-traumatic stress disorder, survivor guilt and substance use--a study of hospitalised Nigerian army veterans. S Afr Med J. 2006;96(2):144-6.
42. US Department of Veterans Affairs: PTSD: National Center for PTSD: PTSD Checklist for DSM-5 (PCL-5). 2020, https://www.ptsd.va.gov/professional/ assessment/adult-sr/ptsd-checklist.asp.

43. WHO: Clinical care for survivors of Ebola virus disease. Interim Guidance. 2016 http://apps.who.int/iris/bitstream/10665/204235/1/WHO_EVD_OHE_ PED_16.1_eng.pdf?ua=1.

44. Mohammed H, Vandy AO, Stretch R, Otieno D, Prajapati M, Calderon M, Vandi M. Sequelae and other conditions in Ebola virus disease survivors, Sierra Leone, 2015. Emerg Infect Dis. 2017;23(1):66-73.

45. Matua GA, Van der Wal DM. Living under the constant threat of Ebola: a phenomenological study of survivors and family caregivers during an Ebola outbreak. J Nurs Res. 2015;23(3):217-24.

46. Locsin RC, Barnard A, Matua AG, Bongomin B. Surviving Ebola: understanding experience through artistic expression. Int Nurs Rev. 2003;50(3):156-66.

47. De Roo A, Ado B, Rose B, Guimard Y, Fonck K, Colebunders R. Survey among survivors of the 1995 Ebola epidemic in Kikwit, Democratic Republic of Congo: their feelings and experiences. Tropical Med Int Health. 1998; 3(11):883-5

48. Mohammed A, Sheikh TL, Gidado S, Poggensee G, Nguku P, Olayinka A, Ohuabunwo C, Waziri N, Shuaib F, Adeyemi J, et al. An evaluation of psychological distress and social support of survivors and contacts of Ebola virus disease infection and their relatives in Lagos, Nigeria: a cross sectional study - 2014. BMC Public Health. 2015;15(1):1-8.

49. Rabelo I, Lee V, Fallah MP, Massaquoi M, Evlampidou I, Crestani R, Decroo T, Van den Bergh R, Severy N. Psychological distress among Ebola survivors discharged from an Ebola treatment unit in Monrovia, Liberia - A Qualitative Study. Front Public Health. 2016:4:142.

50. Bakare WA, llesanmi OS, Nabena EP, Famuyide T. Psychosocial stressors and support needs of survivors of Ebola virus disease, Bombali District, Sierra Leone, 2015. Healthc Low-Resource Settings. 2015;3(2):48-51.

51. Ji D, Ji YJ, Duan XZ, Li WG, Sun ZQ, Song XA, Meng YH, Tang HM, Chu F, Niu XX, et al. Prevalence of psychological symptoms among Ebola survivors and healthcare workers during the 2014-2015 Ebola outbreak in Sierra Leone: a cross-sectional study. Oncotarget. 2017;8(8):12784-91.

52. Karafillakis E, Jalloh MF, Nuriddin A, Larson HJ, Whitworth J, Lees $S$, Hageman KM, Sengeh $P$, Jalloh MB, Bunnell $R$, et al. 'Once there is life, there is hope' Ebola survivors' experiences, behaviours and attitudes in Sierra Leone, 2015. BMJ Glob Health. 2016;1(3):e000108.

53. Bowen L, Smith B, Steinbach S, Billioux B, Summers A, Azodi S, Ohayon J, Schindler M, Nath A. Survivors of Ebola virus disease have persistent neurological deficits (S53. 003). Neurology. 2016;86(16 Supplement):S53. 003.

54. Keita MM, Taverne B, Savané SS, March L, Doukoure M, Sow MS, Touré A, Etard JF, Barry M, Delaporte E. Depressive symptoms among survivors of Ebola virus disease in Conakry (Guinea): preliminary results of the PostEboGui cohort. BMC Psychiatry. 2017;17:1-9.

55. Brown JC, Huedo-Medina TB, Pescatello LS, Ryan SM, Pescatello SM, Moker E, LaCroix JM, Ferrer RA, Johnson BT. The efficacy of exercise in reducing depressive symptoms among cancer survivors: a meta-analysis. PLoS One. 2012;7(1):e30955.

56. Aylett $\mathrm{E}$, Small N, Bower P. Exercise in the treatment of clinical anxiety in general practice - a systematic review and meta-analysis. BMC Health Serv Res. 2018;18(1):559.

57. Mak IWC, Chu CM, Pan PC, Yiu MGC, Ho SC, Chan VL. Risk factors for chronic post-traumatic stress disorder (PTSD) in SARS survivors. Gen Hosp Psychiatry. 2010;32(6):590-8.

58. McLean CP, Asnaani A, Litz BT, Hofmann SG. Gender differences in anxiety disorders: prevalence, course of illness, comorbidity and burden of illness. J Psychiatr Res. 2011;45(8):1027-35.

59. Ford DE, Erlinger TP. Depression and C-reactive protein in US adults: data from the third National Health and nutrition examination survey. Arch Intern Med. 2004;164(9):1010-4.

60. Davydow DS, Desai SV, Needham DM, Bienvenu OJ. Psychiatric morbidity in survivors of the acute respiratory distress syndrome: a systematic review. Psychosom Med. 2008;70(4):512-9.

61. Betancourt TS, McBain R, Newnham EA, Akinsulure-Smith AM, Brennan RT, Weisz JR, Hansen NB. A behavioral intervention for war-affected youth in Sierra Leone: a randomized controlled trial. J Am Acad Child Adolesc Psychiatry. 2014;53(12):1288-97.

62. Bolton $P$, Bass J, Neugebauer R, Verdeli $H$, Clougherty KF, Wickramaratne P, Speelman L, Ndogoni L, Weissman M. Group interpersonal psychotherapy for depression in rural Uganda: a randomized controlled trial. JAMA. 2003;289(23):3117-24. 
63. Petersen I, Bhana A, Baillie K, Mha PPRPC. The feasibility of adapted groupbased interpersonal therapy (IPT) for the treatment of depression by community health workers within the context of task shifting in South Africa. Community Ment Health J. 2012;48(3):336-41.

\section{Publisher's Note}

Springer Nature remains neutral with regard to jurisdictional claims in published maps and institutional affiliations.

Ready to submit your research? Choose BMC and benefit from:

- fast, convenient online submission

- thorough peer review by experienced researchers in your field

- rapid publication on acceptance

- support for research data, including large and complex data types

- gold Open Access which fosters wider collaboration and increased citations

- maximum visibility for your research: over $100 \mathrm{M}$ website views per year

At $\mathrm{BMC}$, research is always in progress.

Learn more biomedcentral.com/submissions 